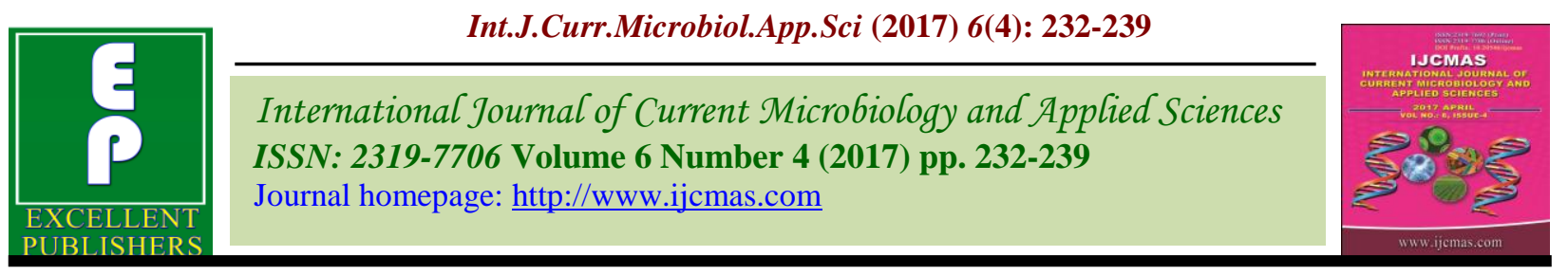

Original Research Article

https://doi.org/10.20546/ijcmas.2017.604.027

\title{
The Biochemical Status of Robusta Coffee (Coffea canephora) Influenced by Organic and Integrated Nutrient Management Practices
}

\author{
S.B. Hareesh ${ }^{1}$, Jayarama ${ }^{2}$, Maria Violet D'Souza ${ }^{2}$ and J. Keshavayya ${ }^{3}$ \\ ${ }^{1}$ Regional Coffee Research Station, Thandigudi, Dindigul District, Tamil Nadu - 624216, India \\ ${ }^{2}$ Division of Agricultural Chemistry, Central Coffee Research Institute, \\ Chikmagalur District - 577 117, Karnataka, India \\ ${ }^{3}$ Department of Chemistry, Kuvempu University, Shankarghatta, \\ Shimoga District - 577 451, Karnataka, India \\ *Corresponding author
}

\section{A B S T R A C T}

In India, among different cultivars of robusta coffee, S.274 has become more popular due to its wide adaptability and its bold beans character. The current field experiment was conducted to know the effect of organics and INM method of nutrition, shade pattern and

Keywords irrigation schedule on the leaf carbohydrate status and yield of genotype S.274. The

Carbohydrate reserves, Integrated nutrition, Irrigation, Robusta coffee, Shade and yield.

\section{Article Info}

Accepted: 02 March 2017 Available Online: 10 April 2017 carbohydrate economy of the plant is usually regarded as an integrated system of sources and sinks. Present experiment shows that, both organic and INM methods of nutrition had a significant effect on leaf carbohydrates and product. In general, the carbohydrate and starch concentration remain higher (9.5 and 5.0 \%, respectively) in INM mode compared to that of exclusive organics $(9.1$ and $4.7 \%$, respectively). Similarly the optimum shade condition, leaf carbohydrates significantly higher in both INM and organic treatments $(9.8$ and $9.6 \%$ ) compared to thick shade $(9.2$ and $8.6 \%)$. The winter irrigation resulted in significantly higher leaf carbohydrate (11.1 and 10.3\%) accumulation compared to the leaves under blossom and backing irrigation (7.9\%). The average bean yield over two years under different treatments remained higher (1230 kg ha-1) in INM mode of nutrition compared to that of exclusive organics (1101 kg ha-1). It may be due to higher carbohydrates status in the INM method. Since reserve carbohydrate could be utilized by the plants for development coffee beans during fruit filling stage besides supporting fresh vegetative sprouts meant for bearing in the subsequent season.

\section{Introduction}

In general sustainability of coffee yield depends on the carbohydrate reserves. Sufficient carbohydrates are necessary to produce vegetative and reproductive growth. The stored carbohydrates reserves in the plants, the starch will be hydrolyzed and utilized by plant for its growth and development (Kozlowski and Keller, 1966 and Anders Ericsson, 1978). Shade grown coffee is known for best quality because of its uniform maturity of fruits due to soluble sugars in fruits. The sugars have positive correlations with better cup quality attributes and most desirable green bean physical characteristics. Meanwhile, the deficiency of carbohydrates in the coffee plant leads to 
berry drop and bean disorders such as black bean, floats etc. Nutrients are indispensable as plant constituents for biochemical reactions and for the production of organic compounds (carbohydrates, proteins etc.) by photosynthesis. Nutrient supplied either through organic or chemical means will be converted into assimilation required for growth and development of the plants (Robertson et al., 2000). In perennial crops, the nutrition deficiency limits the utilization of carbohydrate more than the photosynthetic activity. Generally lower plant performance observed in the case of organic compared to conventional systems, due to slow release of nutrients by organic manures in comparison with mineral fertilizers. Long term fertilizer trials at Central Coffee Research Institute have revealed that $10: 7: 10 \mathrm{~kg}$ NPK is required to produce $100 \mathrm{~kg}$ clean coffee besides a sustenance dose of 20:20:20 kg NPK for promoting vegetative growth by considering fertilizer use efficiency (Jayarama, 2001). The supplementary and complementary use of organic manure is well-known for increasing the efficiency of mineral fertilizers. At this juncture, integrated nutrition management with adequate importance to organic sources of nutrients would be a viable option for sustainable agriculture. With this context the current study was planned to elucidate the carbohydrate assimilation in the leaf tissues and in turn yields realized as influenced by different method of nutrition (organics and INM), shade pattern and irrigation schedule.

\section{Materials and Methods}

Current field experiments were conducted in selected robusta coffee estates of Koppa region, Chikmagalur District, Karnataka state, India. Among the estates, four estates practice organic mode of nutrition, while four estates follow integrated nutrition management practice and one estate where no nutrition management is practiced (absolute control).
Varying shade pattern (open and thick) and irrigation (blossom, backing and winter) are the differentiation factors in the selected estates practicing exclusive organic cultivation and integrated nutrient management. The experiment was laid out in randomized block design (RBD) with 25 plants per treatment (plot size- $112 \mathrm{~m} 2$ ) with four replications. The selected estates under organic cultivation were practicing organic farming since preceding four years. The other cultural practices were carried out as per the package of practices (Anonymous, 2003). The third pair of representative leaf samples from all nine robusta growing coffee estates was collected and processed following the standard method of leaf sampling. Leaf samples were collected during pre-monsoon (March-April) and post-monsoon season (Sept-Oct) from the experimental blocks. The leaf biochemical constituents were then determined by adopting standard methods of analysis. The carbohydrate content in the alcoholic extract was determined by using anthrone method as described by Sadasivam and Manickam (1991), starch content by Patel (1970), reducing sugar and total sugar by Nelson-Somogyi method as described by Sadasivam and Manickam (1991) and nonreducing sugar content by Pallavi Mishra and Dubey (2008). The data was subjected to appropriate statistical analysis as suggested by Gomez and Gomez (1984) to draw valid inferences. The treatment details are as follows

T1- Control

T2- Organic nutrition, thick shade (TS-50 to $60 \%$ canopy) + Irrigation 1 (winter)*

T3- Organic nutrition, thick shade (TS-50 to $60 \%$ canopy) + Irrigation (Blossom and Backing) $2 *$

T4-Organic nutrition, optimum shade (OS-25 to $30 \%$ canopy) + Irrigation (Blossom and Backing) 2*

T5- Organic nutrition, optimum shade (OS-25 
to $30 \%$ canopy) + Irrigation1 (winter)*

T6- INM, thick shade (TS -50 to $60 \%$ canopy) + Irrigation1 (winter)\#

T7- INM, thick shade (TS -50 to $60 \%$ canopy) + Irrigation (Blossom and Backing) 2\#

T8- INM, optimum shade (OS-25 to $30 \%$ canopy) + Irrigation (Blossom and Backing)2\#

T9- INM, optimum shade (OS-25 to $30 \%$ canopy) + Irrigation1 (winter)\#

* Organic nutrition-100\% organics [Farm Yard Manure and Compost -2.5 tones ha-1, Rock phosphate 0.2 tones ha-1], \# Integrated nutrition $[50 \%$ recommended dose of fertilizer (Anonymous, 2003) $+50 \%$ organic manures]

1 Irrigation: At least four irrigations at winter, blossoming, backing and summer (interval of twenty days), extended if dry spell continuous (winter-irrigation),

2 Irrigation: Irrigations at blossoming and backing (blossom backing irrigation)

\section{Results and Discussion}

In the present study, the leaf carbohydrate and starch concentration remained higher $(9.5$ and $5.0 \%$, respectively) in INM method of nutrition compared to that of organic method (9.1 and 4.7\%, respectively). The shade pattern and irrigation schedule imparted difference in carbohydrate and starch accumulation. The leaf carbohydrate and starch content in both INM (9.8 and $5.2 \%$ ) and organic (9.6 and $4.9 \%$ ) treatments at optimum shade conditions were observed higher than the INM (9.2 and $4.7 \%)$ and organic (8.6 and $4.5 \%$ ) treatments at thick shade. Similarly, the leaf carbohydrate and starch content in both INM (11.1 and 5.5\%) and organic (10.3 and 5.1\%) treatments at winter irrigations were more than the INM (7.9 and $4.45 \%$ ) and organic (7.9 and $4.35 \%$ ) treatments at thick shade. In general the total sugar content remains higher $(4.7 \%)$ in INM method of nutrition compared to organic (4.3\%) method. The optimum shade resulted in slightly higher leaf total sugar at INM and organic treatments (5.0 and 4.7\%) compared to thick shade at INM and organic treatments (4.5 and $3.8 \%$ ). Similarly, winter irrigation revealed higher total sugar accumulation at INM and organic treatments (5.7 and 5.0\%) compared to the leaves under blossom and backing irrigation at INM and organic treatments (3.8 and 3.6\%). On the contrary, the leaf reducing sugar concentration remains higher $(2.0 \%)$ in plants receiving organic method of nutrition compared to INM (1.7\%). The optimum shade resulted in slightly elevated leaf reducing sugar in organic and INM method of nutrition (2.1 and 1.8\%) compared to the thick shade in organic and INM method of nutrition (1.8 and 1.6\%). Similarly, higher (2.2 and $2.1 \%$ ) leaf reducing sugar accumulation was observed in plants subjected to blossom and backing irrigation compared to the plants under winter irrigation (1.7 and 1.3\%). Whereas, in all the treatments the non-reducing sugars remains higher than reducing sugars irrespective of nutrition methods, shade pattern and irrigation schedule. In general the non-reducing sugar concentration was higher $(3.0 \%)$ in INM of nutrition compared to that of organics method (2.3\%). Within INM and organic method of nutrition, the shade pattern and irrigation schedule imparted difference in non-reducing sugar accumulation. The optimum shade resulted in slightly elevated leaf non-reducing sugar content in INM and organic method (3.2 and 2.6\%) compared to thick shade in INM and organic method (2.9 and 2.0\%). Similarly, higher (4.3 and 3.3\%) leaf nonreducing sugar accumulation was recorded in plants of winter irrigation only compared to the plants of blossom and backing irrigation (1.7 and 1.4\%). The results are presented in table 1 and 2 . 
In the present experiment attempts were made to describe the effective concentrations of biochemical constituent's status at pre and post monsoon season. As carbohydrates are concerned, the INM method facilitated higher $(10.5 \%)$ accumulation in the leaf compared to that of organic method $(7.7 \%)$. However, higher carbohydrates might be accumulated in the INM method due to blossoming and berry formation. Thus higher carbohydrates remains in the INM method could be utilized by the plants during fruit development stage besides supporting fresh vegetative and reproductive growth for subsequent season. In contrast, the starch concentration was found to be increased $(17 \%)$ in organic compared to INM method of nutrition (15.2\%). The total sugars concentrations were found to be decreased $(2.3 \%)$ in organic method of nutrition whereas; it is unchanged in case of INM method. The percentage of reducing sugars decreased $(15.0 \%)$ in organic method of nutrition, but it was 11.0 per cent in the INM method. The drastic reduction of reducing sugars in organic method of nutrition may be attributed to higher metabolic activities of plants in the organic method of nutrition. In contrast, the non-reducing sugar concentration was increase $(10.5 \%)$ in the INM compared to that of organic method $(7.7 \%)$. The analytical results are depicted in figure 1 and 2.

The comparisons made between the two seasons with respect to leaf biochemical components revealed that, the carbohydrates increased under thick and optimum shade pattern (5.7 and $7.1 \%$ respectively); though the there was no perceptible differences were observed in both shade pattern. It is evident that carbohydrate synthesis is dependent on nitrogen assimilation could be higher in the optimum shade pattern which might be results in higher carbohydrate accumulation. However, the winter irrigation maintained higher carbohydrate synthesis in both the seasons between the sampling intervals
(16.0\%) compared to that of blossom and backing $(8.7 \%)$ irrigations. In the blossom and backing irrigation initially the carbohydrate synthesis was reduced it may be due to inadequate moisture, but it was recouped with the onset of monsoon. No perceptible differences were observed in starch content of the leaf under both thick shade $(15.2 \%)$ and optimum shade $(15.7 \%)$ pattern. However, the synthesis of starch was accelerated (18.2\%) under blossom and backing irrigation compared to winter irrigation (13.2\%). This explains that the prevailing stress in the blossom and backing irrigation schedule was modulated to synthesize more starch under favorable conditions after the onset of monsoon. Similarly, the reducing sugar was highly decreased $(15.0 \%)$ in blossom and backing irrigation compared to that of winter irrigation $(9.8 \%)$. Similarly, the decline in reducing sugars was higher $(14.5 \%)$ under thick shade compared to optimum shade $(13.0 \%)$. The two years average of coffee yield under differential shade pattern and irrigation schedule with organic and INM methods is elucidated in figure 3. In general, the maximum average yield (1230 kg ha-1) was observed in INM method of nutrition compared to that of organic (1101 kg ha $\left.{ }^{-1}\right)$. Similar results were reported by Wang et al., (2002). Within INM and organic method of nutrition, the shade pattern and irrigation schedule imparts difference in yield realization. The optimum shade results in slightly higher (1345 and $1410 \mathrm{~kg} \mathrm{ha}^{-1}$ ) yield compared to thick shade (856 and $1050 \mathrm{~kg}$ ha1). Similarly, winter irrigation revealed that higher $\left(1470\right.$ and $\left.1652 \mathrm{~kg} \mathrm{ha}^{-1}\right)$ yield compared to the blossom and backing irrigation (731 and $\left.809 \mathrm{~kg} \mathrm{ha}^{-1}\right)$. The maximum (1875 $\mathrm{kg} \mathrm{ha}^{-1}$ ) yield was observed in the treatment with INM nutrition method under optimum shade and winter irrigation followed by organic $\left(1790 \mathrm{~kg} \mathrm{ha}^{-1}\right)$. 
Table.1 Effect of organic and integrated nutrition on leaf biochemical status during pre monsoon period

\begin{tabular}{|c|c|c|c|c|c|}
\hline Treatments & $\begin{array}{c}\text { Carbohydrates } \\
(\boldsymbol{\%})\end{array}$ & $\begin{array}{c}\text { Starch } \\
(\boldsymbol{\%})\end{array}$ & $\begin{array}{c}\text { Total } \\
\text { Sugar }(\boldsymbol{\%})\end{array}$ & $\begin{array}{c}\text { Reducing Sugar } \\
(\boldsymbol{\%})\end{array}$ & $\begin{array}{c}\text { Non reducing }- \\
\text { sugar (\%) }\end{array}$ \\
\hline T 1 & 6.8 & 3.7 & 3.0 & 1.0 & 2.0 \\
\hline T 2 & 9.6 & 4.7 & 4.3 & 1.4 & 2.9 \\
\hline T 3 & 7.7 & 4.3 & 3.4 & 2.2 & 1.2 \\
\hline T 4 & 8.2 & 4.4 & 3.8 & 2.2 & 1.6 \\
\hline T 5 & 11.0 & 5.4 & 5.6 & 2.0 & 3.6 \\
\hline T 6 & 10.6 & 5.1 & 5.5 & 1.3 & 4.2 \\
\hline T 7 & 7.8 & 4.3 & 3.5 & 1.9 & 1.6 \\
\hline T 8 & 8.0 & 4.6 & 4.1 & 2.2 & 1.9 \\
\hline T 9 & 11.6 & 5.8 & 5.8 & 1.4 & 4.5 \\
\hline Sem +/- & 0.51 & 0.39 & 0.53 & 0.19 & 0.40 \\
\hline CD at 5\% & $\mathbf{1 . 0 5}$ & $\mathbf{0 . 7 9}$ & $\mathbf{1 . 1 0}$ & $\mathbf{0 . 4 0}$ & $\mathbf{0 . 8 2}$ \\
\hline
\end{tabular}

Table.2 Effect of organic and integrated nutrition on leaf biochemical status during postmonsoon period

\begin{tabular}{|c|c|c|c|c|c|}
\hline Treatments & $\begin{array}{c}\text { Carbohydrates } \\
(\boldsymbol{\%})\end{array}$ & $\begin{array}{c}\text { Starch } \\
(\boldsymbol{\%})\end{array}$ & $\begin{array}{c}\text { Total Sugar } \\
(\mathbf{\%})\end{array}$ & $\begin{array}{c}\text { Reducing } \\
\text { Sugar }(\boldsymbol{\%})\end{array}$ & $\begin{array}{c}\text { Non reducing- } \\
\text { sugar (\%) }\end{array}$ \\
\hline T 1 & 6.7 & 3.7 & 3.0 & 0.5 & 2.6 \\
\hline T 2 & 10.1 & 5.7 & 4.4 & 1.3 & 3.1 \\
\hline T 3 & 7.9 & 4.6 & 3.3 & 1.8 & 1.5 \\
\hline T 4 & 9.3 & 5.4 & 3.8 & 2.0 & 1.8 \\
\hline T 5 & 11.9 & 6.3 & 5.6 & 1.8 & 3.8 \\
\hline T 6 & 11.3 & 5.8 & 5.5 & 1.1 & 4.4 \\
\hline T 7 & 8.8 & 5.3 & 3.5 & 1.6 & 1.9 \\
\hline T 8 & 9.7 & 5.5 & 4.1 & 1.9 & 2.2 \\
\hline T 9 & 12.2 & 6.4 & 5.8 & 1.3 & 4.5 \\
\hline Sem +/- & 0.63 & 0.40 & 0.64 & 0.19 & 0.30 \\
\hline CD at 5\% & $\mathbf{1 . 3 0}$ & $\mathbf{0 . 8 3}$ & $\mathbf{1 . 3 2}$ & $\mathbf{0 . 3 8}$ & $\mathbf{0 . 6 3}$ \\
\hline
\end{tabular}

* Average of 2 years analytical data 
Fig.1 Variation of carbohydrate and starch during pre and post monsoon period

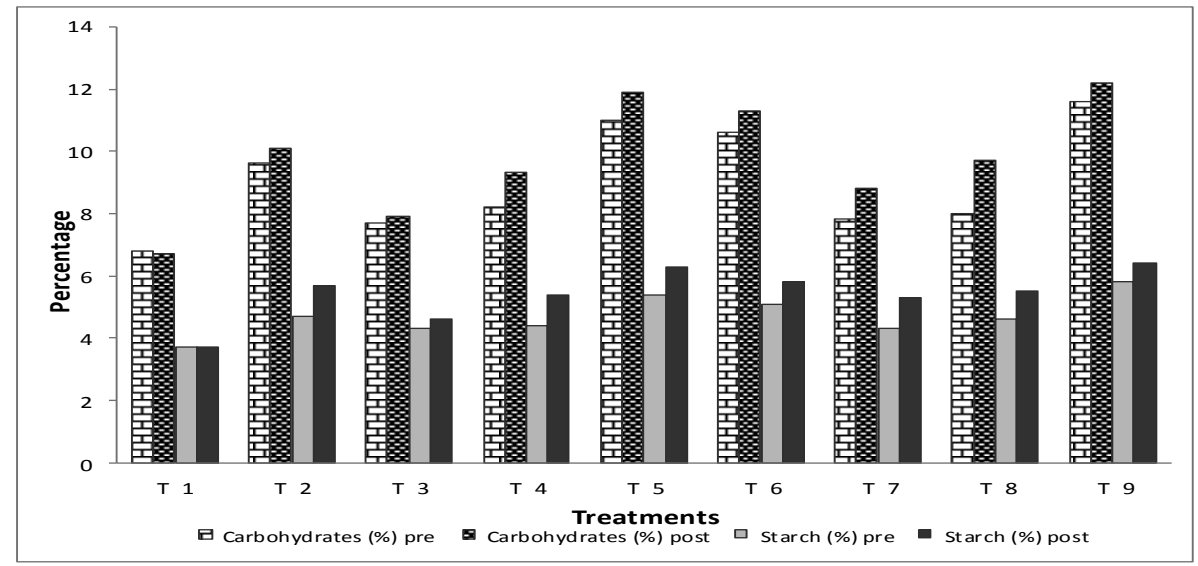

Fig.2 Variation of total, reducing and non-reducing sugars during pre and post monsoon period

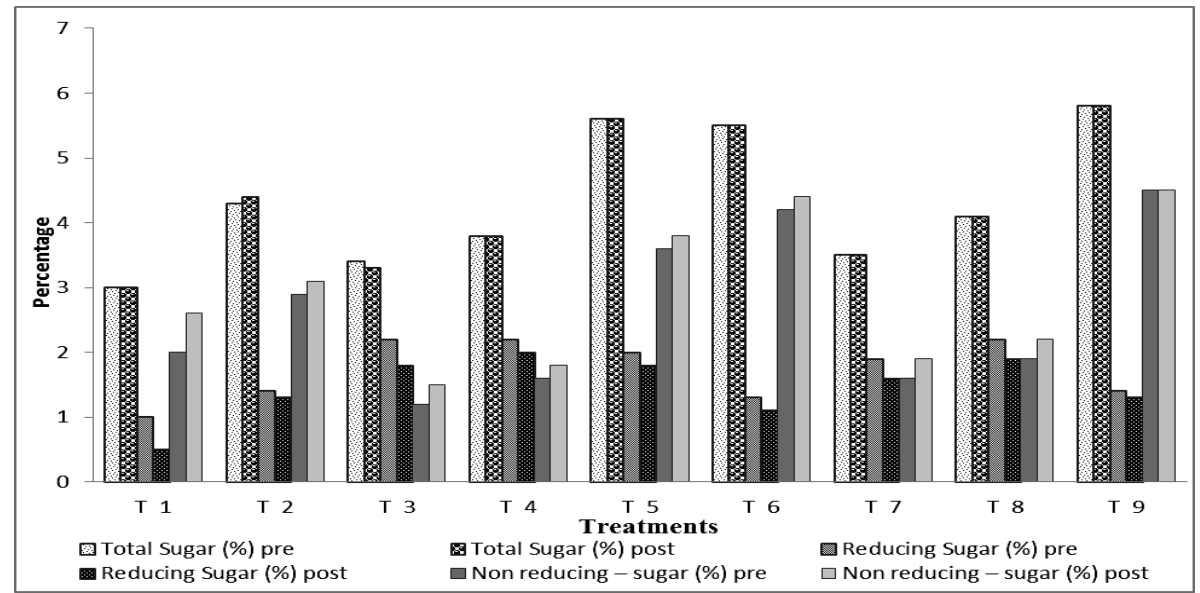

Fig.3 Yield (cc kg/ha) of robusta coffee influenced by organic and integrated nutrition with varying shade and irrigation management practices

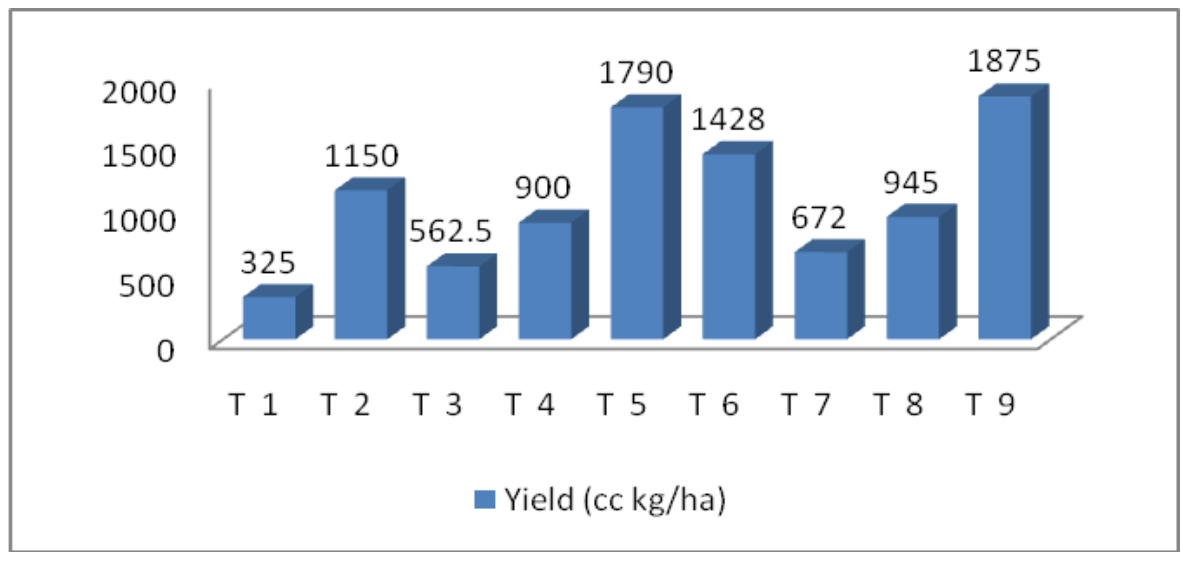


Both crop load and shading can affect leaf carbohydrate concentrations in plants (Jifon and Syvertsen, 2001). In the present study, overall, carbohydrate and starch accumulation in the leaf was favored by INM method of nutrition, besides additive effects seen under open shade and winter irrigation. Similarly, the leaf carbohydrate and starch concentration remained higher in INM method of nutrition compared to that of exclusive organic method of nutrition. On the contrary, the leaf reducing sugar concentration remains higher in plants receiving organic method of nutrition compared to INM. Higher reducing sugars in the organic method indicated minimum loss of sugars in leaf it could be due to plant utilization efficiency. While low reducing sugar reported in the INM it may be attributed to the more rapid utilization by respiration. Similar observations have been reported by Kerenhap et al., (2007) in Mulberry plants applied with different organic manures. The reducing sugar concentration is one of the tools to assess the stress under field conditions of cropping system; it clearly indicated that limited irrigation during blossom and backing as well as thick shade might be serious constraints for achieving anticipated productivity. Carbohydrate source-sink relationships between photosynthetic source leaves and vegetative/reproductive growth sinks determine tree growth and fruit yield (Flore and Lakso, 1986; Nii, 1997 and Goldschmidt, 1999). In a perennial plant such as coffee, consistent crop yield depends on the variables in plant internal and external factors. The nutrition, shade pattern and irrigation are important factors that have great impact on the anticipated yield. The optimum shade was found to be superior when compared to thick shade in imparting favorable environment which is reflected in higher yield. Similarly, the winter irrigation was found to be better over the blossom and backing irrigations for improvement carbohydrate reserve status. The incorporation of integrated nutrition method under optimum shade pattern with winter irrigation was found to be optimum for achieving higher yield in coffee cultivation.

\section{References}

Anders Ericsson.1978. Effects of Fertilization and Irrigation on the Seasonal Changes of Carbohydrate Reserves in Different Age Classes of Needle on 20-Year-Old Scots Pine Trees (Pinus silvestris). Physiol. Plant, 45: 270-280.

Anonymous. 2003. Coffee guide, Published by Coffee Board, India.

Flore, J.A. and Lakso, A.N. 1986. Environmental and physiological regulation of photosynthesis in fruit crops. Hortic. Rev., 11: 111-157.

Goldschmidt, E.E. 1999. Carbohydrate supply as a critical factor for citrus fruit development and productivity. Hort Sci., 34: 1020-1024.

Gomez, K.A. and Gomez, A.A (eds). 1984. Two factor experiments In: Statistical Procedure for Agricultural Research. New York. Wiley.

Jayarama. 2001. Optimal Nutrient Rates and their Best Management in Coffee Plantations. Indian Coffee, Vol. 8-14.

Jifon, J.L. and J.P. Syvertsen. 2001. Effects of moderate shade on Citrus leaf gas exchange, fruit yield and quality. Proc. Fla. State Hortic. Soc., 114: 177-181.

Kerenhap, W., Thiagarajan, V and Kumar, V. 2007. Biochemical and bioassay studies on the influence of different organic manures on the growth of Mulberry Variety V1 and silkworm, Bombyx mori Linn. Caspian J. Env. Sci., 5(1): 51-56.

Kozlowski, T.T and Keller, T. 1966. Food relations of woody plants. Bot. Rev., 32: 293-382.

Nii, N. 1997. Changes of Starch and Sorbitol in Leaves Before and After Removal of Fruits from Peach Trees. Annals of Bot., 
79: 139- 144

Pallavi Mishra and R.S. Dubey. 2008. Effect of aluminium on metabolism of starch and sugars in growing rice seedlings. Acta Physiol. Plant, 30: 265-275.

Patel, A.Z. 1970. A note on seasonal variation in starch content of different parts of arabica coffee. East African Agri. Forestry J., 36(1): 1-6.

Robertson, G.P., Paul, E.A., Harwood, R.R. 2000. Greenhouse gases in intensive agriculture: Contributions of individual gases to the radiative forcing of the atmosphere. Sci., 289: 1922- 1925.
Sadasivam, S and Manickam, A. 1991. Biochemical methods, second edition. New age publications, New Delhi.

Swarna Kumer Mitra. 1921. Seasonal changes and translocation of carbohydrate materials in fruit spurs and two-year-old seedlings of apple. The Ohio J. Sci., Vol. XXI. No. 3. 89- 103.

Wang, J., Shen, H., Sun, J., Zhen, G., Liu, H., Li, Y., Zhao, B and Zhang, F. 2002. Effect of long-term fertilization on crop yield, fertilizer and water use efficiency. Plant Nutr. Fert. Sci., 8: 82-6.

\section{How to cite this article:}

Hareesh, S.B., Jayarama, Maria Violet D'Souza and Keshavayya, J. 2017. The Biochemical Status of Robusta coffee (Coffea canephora) Influenced by Organic and Integrated Nutrient Management Practices. Int.J.Curr.Microbiol.App.Sci. 6(4): 232-239. doi: https://doi.org/10.20546/ijcmas.2017.604.027 